\title{
The Forex Regime and EMU Expansion
}

\author{
Pieter W. van Foreest ${ }^{1}$
}

Casper G. de Vries 1,2

${ }^{1}$ Faculty of Economics, Erasmus University Rotterdam, and Tinbergen Institute,

2 Eurandom 
Tinbergen Institute

The Tinbergen Institute is the institute for economic research of the Erasmus Universiteit Rotterdam, Universiteit van Amsterdam and

Vrije Universiteit Amsterdam.

Tinbergen I nstitute Amsterdam

Keizersgracht 482

1017 EG Amsterdam

The Netherlands

Tel.: +31.(0)20.5513500

Fax: $\quad+31 .(0) 20.5513555$

Tinbergen Institute Rotterdam

Burg. Oudlaan 50

3062 PA Rotterdam

The Netherlands

Tel.: $\quad+31 .(0) 10.4088900$

Fax: $\quad+31 .(0) 10.4089031$

Most TI discussion papers can be downloaded at

http://www.tinbergen.nl 


\title{
The Forex Regime and EMU Expansion*
}

\author{
Pieter W. VAN Foreest \\ Tinbergen Institute \& Erasmus University Rotterdam \\ CAsper G. DE VRIES \\ Tinbergen Institute, Erasmus University Rotterdam \& Eurandom
}

January 2002

\begin{abstract}
This paper provides empirical evidence that, irrespective of the foreign exchange rate regime, countries with high monetary volatility have lower relative output growth rates. It is argued that due to the forward looking nature of the foreign exchange market, exchange rate stability hinges on the stability of the institutional structure within which monetary and fiscal policies are formulated. Subsequently, the likely endogenous response in the accession countries upon entry into EU and EMU is examined. This provides arguments for a rapid transition phase, possibly complemented by a one sided euroisation as a commitment device.
\end{abstract}

Keywords: Exchange Rate Regime, Growth, EMU, CEECs. JEL Codes: E52, F31, F33.

\footnotetext{
${ }^{*}$ Corresponding author: P.W. van Foreest; Address: P.O. Box 1738, 3000 DR, Rotterdam. Email addresses: vanforeest@few.eur.nl and cdevries@few.eur.nl. We are grateful to Ivo Arnold, Wouter den Haan, and Koen Schoors for many helpful discussions, and Lucio Vinhas de Souza for providing data. We also like to thank the seminar participants at the PHARE workshop "Monetary and Exchange Rate Strategies Related to the Current European Union's Enlargement process", and at the X International "Tor Vergata" Conference on "Financial Integration, Competition, and Risks in the Global Economy". We gratefully acknowledge support from the European Union (project P98-1065-R).
} 


\section{Introduction}

To start right away with the main conclusion, we find that the choice of the foreign exchange rate regime is only of secondary importance for achieving monetary stability and real growth. The empirical evidence is that countries with high monetary volatility have lower relative output growth rates. The growth rates, however, appear not to be affected by the amount of forex variability and the type of forex rate system in place over and above the negative effects stemming from monetary instability. The fact that real growth is insulated from forex variability, after taking into account the monetary instability, is analogous to the well established relative insensitivity of the trade account to forex uncertainty, see for instance Bacchetta and van Wincoop (2000). Within the monetary theory of exchange rates, this insensitivity can be seen as an implication of the forward looking nature of the forex markets. Since the spot exchange rate is determined by the discounted sum of all future expected fundamentals, forex stability hinges on the stability of the institutional structure within which monetary and fiscal policies are formulated. Seen in this way, a flexible forex regime can be very stable, if the current and anticipated monetary and fiscal policies are coherent with the market's forex rate evaluation, as countries like The Netherlands and Switzerland have shown. Conversely, as is illustrated by the lively history of the European Monetary System and other currency arrangements, a managed float or fixed forex system may be unstable.

We continue with an investigation of the likely endogenous response in the financial and real sectors in the Central and Eastern European Countries (CEECs) upon entry in Europe's Economic and Monetary Union (EMU). We show that standard monetary theory predicts that the country-specific financial risk within the accession countries will reduce significantly upon entry. In combination with the forward looking nature of the financial markets, this risk reduction provides a strong argument for a rapid transition. As the cases of Italy and Portugal showed, the perspective of entry brings forward the benefits of eliminating the risk premium from the domestic interest rate.

We also investigate the feasibility of low inflation and stable currency criteria for EMU accession. ${ }^{1}$ Standard arguments imply that it may be very difficult for the accession countries to satisfy the low inflation criterion. For instance, the high-growth entrants will have higher inflation, due to the Balassa-Samuelson effects. In fact, currently consumer prices and production in Ireland, Spain, and The Netherlands tend to rise faster than in Germany. Furthermore, due to

\footnotetext{
${ }^{1}$ The complete set of EMU accession criteria, or so-called "Copenhagen Criteria", are put down in the Composite Paper, see European Commission (1998).
} 
the Walters' effect, high-inflation countries that peg their currencies to the euro are likely to undergo persistent oscillations in the real interest rate and the real exchange rate. The latter effect is likely to be especially strong in institutionally underdeveloped countries, such as the CEECs. The anticipation of a stable path for the exchange rate in the short run, invites for capital inflows which often bear a pure speculative character, and may reverse themselves on the smallest doubt, recall the Asian and Russian financial crises. Taken together, although EMU entry is advantageous, it may be very difficult for the CEECs to satisfy the EMU accession criteria.

The paper ends in the way it starts, by subscribing to an unconventional recipe. In our opinion the transition phase to EMU can be speeded up for the smaller CEECs by closing the door to the exchange rate mechanism unconditionally. Currently several of CEECs are already on a currency board, for instance Bulgaria, Estland and Lithuania. But, as the history of currency boards shows, interest rates can still reach delirious levels once the public starts to doubt the tenability of the board. Think of, for example, the Hong Kong experience during the Asian crisis, and the present financial crisis in Argentine. Interest rate hikes are also observed in countries with managed currency pegs. For instance, during the EMS crisis the Irish interest rates raised dramatically. Smaller CEECs may opt to cross-out the undesirable interest rate and accession uncertainty through a full scale euroisation upon receipt of the entry (commitment) from the EU. At the same time such an arrangement would make clear that the remaining inflationary pressures are entirely due to real factors, such as the Balassa-Samuelson effect, and cannot be the result of imprudent monetary policy on the side of accession countries.

\section{Choice of Forex Regime and Economic Growth}

In this section we analyze the relationships between the choice of the forex regime, monetary variables, and output. To this end we exploit the monetary theory of the exchange rate empirically and theoretically. Specifically, we estimate the monetary model of the exchange rate on a panel containing the accession and EMU countries. From the estimated model, we calibrate the empirical first and second moments of the models' components country by country. Subsequently, we present evidence implying that countries with high monetary volatility have lower relative output growth rates, but that the exchange rate variability and the type of exchange rate system do not play an additional role in this relationship. We end this section by showing that the forex regime ir- 
relevance result also follows from the forward solution of the monetary model. This solution shows that forex stability derives from the institutional structure within which monetary and fiscal policies are formulated, but for which the type of forex system is relatively unimportant.

\subsection{The Monetary Foreign Exchange Rate Model}

As is well known, the monetary model of the forex consists of two building blocks: the monetarist money demand model and the purchasing power parity supposition. The standard money demand relation in logarithmic format reads

$$
m-p=\tau y-\lambda r+\varepsilon,
$$

where $M=e^{m}$ is money demand, $P=e^{p}$ is the price level, $Y=e^{y}$ is the output, and $r$ is the nominal interest rate. Other plausible restrictions are a positive income elasticity $\tau>0$, and a negative interest semi-elasticity $\lambda>0$. The residual term $\varepsilon$ contains all effects that are not captured by the log-linear money demand model (1). The relative money demand of a country vis-a-vis Germany is

$$
\widetilde{m}-\widetilde{p}=\tau \widetilde{y}-\lambda \widetilde{r}+\widetilde{\varepsilon},
$$

where $\widetilde{x} \equiv x-x_{\text {Germany }}$. The relative money demand model (2) is the first building block of the monetary exchange rate model. When money demand and supply are balanced, equation (2) describes money market equilibrium. Then relative prices are determined uniquely conform the relationship

$$
\widetilde{p}=\beta \widetilde{m}+\lambda \widetilde{r}-\tau \widetilde{y}-\widetilde{\varepsilon},
$$

where we generalized the model by introducing the money elasticity coefficient $\beta=\partial s / \partial \widetilde{m}$. The quintessence of the monetarist theory is the neutrality hypothesis $\beta=1$.

The second building block is the purchasing power parity (PPP) assumption. In absolute form, PPP postulates that goods sell for the same price in two countries. Formally, let $S=e^{s}$ denote the nominal exchange rate (units of local currency per unit foreign currency), then absolute PPP holds if $\widetilde{p}=s$. The absolute form may not hold due to permanent wedges $\kappa$, like transportation costs. The relative form of the PPP only maintains that the price changes 
Table 1: Countries in Panel

\begin{tabular}{llll}
\hline \hline EMU & CEEC & WEST & REST \\
& & & \\
Austria* & Bulgaria & Australia & India \\
Belgium* & Czech Rep & Canada & Israel \\
Finland* & Estonia* & Denmark* & Japan \\
France* & Hungary & Greece* & Korea \\
Italy* & Latvia & Norway & Malaysia \\
Ireland* & Lithuania & New Sealand & Mexico \\
Luxemburg* & Poland & Sweden* & Philippines \\
Netherlands* & Romania & Switserland* & Singapore \\
Portugal* & Slovak Rep. & UK & Thailand \\
Spain* & Slovenia & US & Turkey \\
* Fixed or Managed Regimes vis-a-vis Germany & \\
\hline
\end{tabular}

occur in tandem. Formally, relative PPP holds if

$$
\widetilde{p}=s+\kappa+\nu,
$$

where $\nu$ is a zero mean disturbance term. Substitution into (3) and rearranging renders the monetarist model of the flexible exchange rate

$$
s=\beta \widetilde{m}+\lambda \widetilde{r}-\tau \widetilde{y}-\widetilde{\eta},
$$

where $\widetilde{\eta} \equiv \kappa+\nu+\widetilde{\varepsilon}$. The model predicts that the forex is related to three fundamental economic factors, respectively the relative money supply $\widetilde{m}$, the interest rate differential $\widetilde{r}$, and the output differential $\widetilde{y}$.

In the next sub-section the monetary forex rate model (5) is employed to analyze the relations between the mean and variance of the forex rate changes with the means and variances of the relative changes in the other variables. However, before we can go into this analysis, we first need to estimate the coefficients of model (5). The nonstationarity of the variables permits estimation in levels, but in order to obtain standard errors, we employ the dynamic OLS technique. The coefficients are restricted to be identical across countries. The theoretical reason for this restriction is that the structural model is not countryspecific. Another reason is that per country time series estimates usually fail to deliver meaningful results, since countries do not often change their monetary regimes. But across countries, monetary regimes do differ substantially, and 
Table 2: Panel Dynamic OLS Regressions

\begin{tabular}{|c|c|c|c|c|c|}
\hline & $c$ & $\beta$ & $\lambda$ & $\tau$ & AEG \\
\hline $\begin{array}{l}A L L \\
\text { ( } 871 \text { observations) }\end{array}$ & $\begin{array}{r}0.006 \\
(0.020) \\
(0.304)\end{array}$ & $\begin{array}{r}0.860 \\
(0.035) \\
(24.760)\end{array}$ & $\begin{array}{r}-1.433 \\
(1.045) \\
(-1.371)\end{array}$ & $\begin{array}{r}-0.901 \\
(0.141) \\
(-6.372)\end{array}$ & $\begin{array}{r}-0.242 \\
(0.088) \\
(-2.761)\end{array}$ \\
\hline $\begin{array}{l}W E S T+R E S T \\
(437 \text { observations })\end{array}$ & $\begin{array}{r}0.055 \\
(0.018) \\
(3.051)\end{array}$ & $\begin{array}{r}0.762 \\
(0.023) \\
(33.048)\end{array}$ & $\begin{array}{r}1.724 \\
(0.459) \\
(3.758)\end{array}$ & $\begin{array}{r}-0.595 \\
(0.089) \\
(-6.714)\end{array}$ & $\begin{array}{r}-0.432 \\
(0.081) \\
(-5.354)\end{array}$ \\
\hline $\begin{array}{l}C E E C \\
\text { ( } 219 \text { observations) }\end{array}$ & $\begin{array}{r}-0.030 \\
(0.087) \\
(-0.346)\end{array}$ & $\begin{array}{r}0.981 \\
(0.041) \\
(23.982)\end{array}$ & $\begin{array}{r}-1.649 \\
(1.269) \\
(-1.299)\end{array}$ & $\begin{array}{r}-1.662 \\
(0.343) \\
(-4.842)\end{array}$ & $\begin{array}{r}-0.219 \\
(0.094) \\
(-2.339)\end{array}$ \\
\hline $\begin{array}{l}E M U \\
\text { ( } 215 \text { observations) }\end{array}$ & $\begin{array}{r}0.048 \\
(0.010) \\
(5.073)\end{array}$ & $\begin{array}{r}-0.121 \\
(0.025) \\
(-4.758)\end{array}$ & $\begin{array}{r}3.079 \\
(0.448) \\
(6.865)\end{array}$ & $\begin{array}{r}-0.016 \\
(0.041) \\
(-0.385)\end{array}$ & $\begin{array}{r}-0.316 \\
(0.095) \\
(-3.324)\end{array}$ \\
\hline $\begin{array}{l}\text { ALL without Bulgaria } \\
\text { ( } 850 \text { observations) }\end{array}$ & $\begin{array}{r}0.033 \\
(0.014) \\
(2.376)\end{array}$ & $\begin{array}{r}0.702 \\
(0.036) \\
(19.500)\end{array}$ & $\begin{array}{r}1.514 \\
(0.439) \\
(3.452)\end{array}$ & $\begin{array}{r}-0.413 \\
(0.099) \\
(-4.160)\end{array}$ & $\begin{array}{c}-0.194 \\
(0.050) \\
(-3.884)\end{array}$ \\
\hline $\begin{array}{l}\text { CEEC without Bulgaria } \\
\text { ( } 198 \text { observations) }\end{array}$ & $\begin{array}{r}0.003 \\
(0.062) \\
(0.042)\end{array}$ & $\begin{array}{r}0.883 \\
(0.047) \\
(18.687)\end{array}$ & $\begin{array}{r}2.971 \\
(0.889) \\
(3.342)\end{array}$ & $\begin{array}{r}-0.555 \\
(0.215) \\
(-2.576)\end{array}$ & $\begin{array}{r}-0.171 \\
(0.077) \\
(-2.213)\end{array}$ \\
\hline
\end{tabular}

Numeraire: Germany; Period: 1994:II 1999:III; Cointegration model (13); Pooled cointegration test (14); In parenthesis: Standard errors (first row) and t-statistics (second row).

hence yield valuable information. A panel with cross country coefficient restrictions can exploit this variation to obtain meaningful parameter estimates. The cross-section coefficient restriction is moreover instrumental for the empirical analysis, given the limited amount of data available for the CEECs. The time series dimension of our CEEC panel data is in fact extremely limited. For the 10 CEECs in our panel we have at most 6 annual observations that are driven by market forces rather than central planning. For this reason we increase the panel's cross-section by adding 30 other countries and increase the time-series dimension by using quarterly observations instead of annual observations. The data set is described in detail in Appendix A.1.

Since we are primarily interested in the behavior of CEECs vis-a-vis EMU, we choose Germany as the numeraire country. To examine the robustness of the estimation results, we repeat the regression for various country groupings. The panel is subdivided into three groups: CEEC, EMU, and WEST+REST. Clearly, CEEC contains the potential Central and Eastern European entrants, while EMU comprises all countries in the European Economic and Monetary 
Union (with exception of the numeraire Germany). The grouping WEST+REST contains industrialized countries which are not in the EMU. The exact composition of the groupings is given by table 1. Since Bulgaria went through an abysmal monetary crisis during the years 1996-97, we also repeat the regression for panels without that country. ${ }^{2}$ The long-run coefficient estimates are reported in table 2. In addition to these estimates of the panel dynamic OLS, we include the pooled Augmented Engle-Granger (AEG) cointegration test statistic in the last column of table 2. To stay focussed on economic issues, we choose to present only the directly relevant empirical results. A discussion on estimation techniques, such as the AEG cointegration tests, and intermediate steps is relegated to the Appendix A.2.

The monetary homogeneity hypothesis $\beta=1$ holds up quite well in the different panels, except when the data are restricted to the EMU countries. But this is not so surprising, since convergence between these countries in the 1994-1999 period in anticipation of the monetary unification gives insufficient variation in the money data to get a reliable estimate. Per contrast, the monetary hyper expansion in Bulgaria during the years 1996-97 is very conducive for producing a reliable estimate of $\beta$. When Bulgaria's data is included, the relative money shocks of the CEECs appear to be completely absorbed by the forex rate, see third row table 2. However, when Bulgaria is dropped from the CEEC group, the money effect is less pronounced, see last row of table 2. One also finds that when the interest data from Bulgaria is included the interest semi-elasticity $\lambda$ turns negative, but insignificantly so. The estimation results are thus seriously affected by the interest rate hike that took place in Bulgaria during the 1996-97 hyper inflation period. ${ }^{3}$ There is furthermore quite some variation in the income elasticity $\tau$, but the estimates are always negative, and mostly significantly so.

An important issue is whether the estimates of coefficients $\beta, \lambda$, and $\tau$ are structural, in the sense of Lucas (1976). Coefficients are probably not structural when panel cointegration is rejected. The last column in table 2 gives the pooled Augmented Engle-Granger (AEG) test statistic for cointegration. Under certain conditions, the asymptotic critical $t$-value equals -3.74 at the $5 \%$ level. $^{4}$ So, convincing evidence for cointegration is found only in case of the WEST and REST grouping. The WEST+REST group estimates appear robust to

\footnotetext{
${ }^{2}$ For a description of Bulgaria's recent monetary history we refer to the IMF policy discussion paper by Gulde (1999).

${ }^{3}$ The Bulgarian lending rate (IFS code 91860P..ZF) in the second quarter of 1996 was around $50 \%$ per annum. Then it started to increase rapidly. At the top, in the first quarter of 1997 , the rate was close to $230 \%$. During 1997 the interest rates fell rapidly to about $13 \%$.

${ }^{4}$ See Appendix section A.2.
} 
Lucas' policy critique. These estimates are theoretically consistent, and pooled cointegration can not be rejected. By contrast, the pooled cointegration tests for the CEEC and EMU group point to strong transition effects. The countries in these groups have clearly not converged to the long run stationary state.

\subsection{Characterization of Monetary Policy Regimes}

In order to characterize empirically the different monetary policy regimes and the trade-offs represented by the different regimes, we assume that each country in the sample has essentially operated one particular regime. This gives "one observation" of the per country variables, and the cross-section provides the overview of alternative regimes. To capture the regime specifics, we estimate per-country the empirical moments of the monetary models' variables. Subsequently, we perform a cross-country rank regression analysis on the sample moments in order to assess how the characteristics of the domestic policy regime are related to the specifics of the forex regime in place, and vice versa. From a policy maker view point, probably the most relevant empirical question to be answered is which type of monetary regime has been associated with the most favorable output growth characteristics.

By defining composite financial variable $f \equiv \beta \widetilde{m}+\lambda \widetilde{r}$ and real variable $g \equiv-\tau \widetilde{y}$, model (5) may be written compactly as $s=f+g+\widetilde{\eta}$. Accordingly, the forex return obeys

$$
\Delta s=\Delta f+\Delta g+\Delta \widetilde{\eta},
$$

where $\Delta$ is the first-difference operator. For a proper interpretation of equation (6), note that, $\Delta g$ and $\Delta \widetilde{y}$ enter the model with opposite signs. Consequently, a country grows faster than Germany if $\Delta g<0$ so that $-\tau \Delta \widetilde{y}>0$. Model (6) imposes a structure on the moments of the forex return process. Let country $i$ 's moments be defined as $\mu_{x, i} \equiv E\left\{\Delta x_{i, t}\right\}, \sigma_{x, i}^{2} \equiv \operatorname{Var}\left\{\Delta x_{i, t}\right\}$, and $\sigma_{x u, i} \equiv$ $\operatorname{Cov}\left\{\Delta x_{i, t}, \Delta u_{i, t}\right\}$, so that the moment decompositions can be expressed as

$$
\begin{aligned}
\mu_{s, i} & =\mu_{f, i}+\mu_{g, i}+\mathcal{E}_{i} \\
\sigma_{s, i}^{2} & =\sigma_{f, i}^{2}+\sigma_{g, i}^{2}+2 \sigma_{f g, i}+\mathcal{U}_{i} .
\end{aligned}
$$

Since the monetary forex rate model (6) contains an unobserved residual $\Delta \widetilde{\eta}$, the moment decompositions (7) contain the unidentified components $\mathcal{E}_{i}$ and $\mathcal{U}_{i}$. In the empirical analysis, $\mathcal{E}_{i}$ and $\mathcal{U}_{i}$ are just residuals.

As explained above, we propose to perform a cross-country rank regression analysis on the empirical moments in order to asses the links across regime 
specifics. Our empirical analysis therefore consists of two steps. In the first step we estimate the empirical first and second moments of the models' components country by country. Specifically, given the panel coefficient estimates $\widehat{\beta}$, $\widehat{\tau}$, and $\widehat{\lambda}$, and the historical panel data on $s_{i, t}, \widetilde{m}_{i, t}, \widetilde{r}_{i, t}$, and $\widetilde{y}_{i, t}$, we construct for each country, $i=1, \ldots, N$, the composite financial variable $f_{i, t} \equiv \widehat{\beta} \widetilde{m}_{i, t}+\widehat{\lambda} \widetilde{r}_{i, t}$ and a real variable $g_{i, t} \equiv-\widehat{\tau} \widetilde{y}_{i, t}$, and estimate the moments (7). In line with our arguments in the previous sub-section, the long-run coefficient estimates are those from the WEST+REST panel estimation. In addition, we calculate the fundamentals' sample correlation coefficient $\rho_{f g, i}=\sigma_{f g, i} \sigma_{f, i}^{-1} \sigma_{g, i}^{-1}$. To interpret $\rho_{f g, i}$ correctly, recall that we defined $\Delta g_{i, t}=-\tau \Delta \widetilde{y}_{i, t}$. Thus positive linear dependence between $\Delta f_{i, t}$ and $\Delta g_{i, t}$ implies negative correlation between $\Delta f_{i, t}$ and $\Delta \widetilde{y}_{i, t}$. As the number of countries is large, it is impracticable to report all empirical moments. We decided to summarize the results of the percountry tests by reporting the cross-sectional mean and standard deviation of each component for the various country groupings in Table 3.

There are pronounced differences between the various regions. In general, growth rates and the variances of all economic variables are remarkably low in the EMU group, while they are substantial in the CEEC group (including and excluding Bulgaria). In general the WEST+REST group has a middle position, except that the WEST+REST forex volatility is substantially higher than in the CEEC excluding Bulgaria. This indicates that CEECs try to stabilize the value of their currencies vis-a-vis Germany. There are noteworthy differences in sample correlations between financial and real growth rates, see table 3 last row. While the $\Delta f_{i, t}$ and $\Delta y_{i, t}$ are on average negatively correlated within EMU, they are on average positively correlated within CEEC. The negative correlation within EMU countries is obviously due to the monetary unification process and the anticipated entry to EMU. On the other hand, the positive correlation in the CEECs points at a lack of monetary prudence. As the numbers in parenthesis show, the cross-sectional standard deviations of the monetary components are very low in the EMU group, while they are extremely high in the CEEC group including Bulgaria. This finding is important for cross-sectional analysis of policy regimes. High cross-sectional variation is very conducive for producing a reliable characterization of policy regimes. Per contrast, cross-sectional analysis is useless when sample moments tend to cluster together, since then one gets just only "one observation" for the whole cross-section. For this reason we decided to exclude the EMU countries from the cross-section analysis.

In the second step of our analysis, we examine the linkages across the moment estimates of the first step. Specifically, in order to disentangle the cross- 
Table 3: Cross-Sectional Averages

\begin{tabular}{|c|c|c|c|c|c|c|}
\hline & $A L L$ & $\begin{array}{c}W E S T \\
+R E S T\end{array}$ & CEEC & $E M U$ & $\begin{array}{c}\text { ALL } \\
\text { - Bulgaria }\end{array}$ & $\begin{aligned} & C E E C \\
- & \text { Bulgaria }\end{aligned}$ \\
\hline$\mu_{s}$ & $\begin{array}{r}1.18 \\
(3.84)\end{array}$ & $\begin{array}{r}0.80 \\
(3.39)\end{array}$ & $\begin{array}{r}3.24 \\
(5.72)\end{array}$ & $\begin{array}{l}-0.11 \\
(0.23)\end{array}$ & $\begin{array}{r}0.80 \\
(3.04)\end{array}$ & $\begin{array}{r}1.83 \\
(3.79)\end{array}$ \\
\hline$\mu_{f}$ & $\begin{array}{r}1.83 \\
(2.81)\end{array}$ & $\begin{array}{r}1.69 \\
(2.89)\end{array}$ & $\begin{array}{r}3.60 \\
(3.08)\end{array}$ & $\begin{array}{r}0.33 \\
(1.01)\end{array}$ & $\begin{array}{r}1.64 \\
(2.59)\end{array}$ & $\begin{array}{r}3.01 \\
(2.59)\end{array}$ \\
\hline$\mu_{g}$ & $\begin{array}{l}-0.25 \\
(0.45)\end{array}$ & $\begin{array}{r}-0.28 \\
(0.36)\end{array}$ & $\begin{array}{r}-0.08 \\
(0.54)\end{array}$ & $\begin{array}{l}-0.37 \\
(0.50)\end{array}$ & $\begin{array}{r}-0.28 \\
(0.41)\end{array}$ & $\begin{array}{r}-0.19 \\
(0.43)\end{array}$ \\
\hline $\mathcal{E}$ & $\begin{array}{r}-0.40 \\
(1.48)\end{array}$ & $\begin{array}{r}-0.62 \\
(0.80)\end{array}$ & $\begin{array}{r}-0.29 \\
(2.73)\end{array}$ & $\begin{array}{l}-0.07 \\
(0.71)\end{array}$ & $\begin{array}{r}-0.56 \\
(1.06)\end{array}$ & $\begin{array}{r}-0.99 \\
(1.65)\end{array}$ \\
\hline$\sigma_{s}^{2}$ & $\begin{array}{r}56.49 \\
(150.36)\end{array}$ & $\begin{array}{r}53.01 \\
(55.49)\end{array}$ & $\begin{array}{r}116.27 \\
(290.41)\end{array}$ & $\begin{array}{r}3.64 \\
(4.89)\end{array}$ & $\begin{array}{r}33.92 \\
(47.99)\end{array}$ & $\begin{array}{r}25.14 \\
(38.12)\end{array}$ \\
\hline$\sigma_{f}^{2}$ & $\begin{array}{r}16.53 \\
(53.35)\end{array}$ & $\begin{array}{r}9.22 \\
(19.68)\end{array}$ & $\begin{array}{r}42.87 \\
(102.07)\end{array}$ & $\begin{array}{r}4.79 \\
(7.43)\end{array}$ & $\begin{array}{r}8.43 \\
(15.13)\end{array}$ & $\begin{array}{r}10.70 \\
(8.99)\end{array}$ \\
\hline$\sigma_{g}^{2}$ & $\begin{array}{r}3.84 \\
(5.24)\end{array}$ & $\begin{array}{r}2.61 \\
(2.48)\end{array}$ & $\begin{array}{r}7.61 \\
(8.88)\end{array}$ & $\begin{array}{r}2.55 \\
(2.46)\end{array}$ & $\begin{array}{r}3.13 \\
(2.71)\end{array}$ & $\begin{array}{r}4.94 \\
(2.94)\end{array}$ \\
\hline$\sigma_{f g}$ & $\begin{array}{r}3.75 \\
(22.12)\end{array}$ & $\begin{array}{r}1.30 \\
(6.88)\end{array}$ & $\begin{array}{r}12.10 \\
(43.76)\end{array}$ & $\begin{array}{r}0.31 \\
(1.28)\end{array}$ & $\begin{array}{r}0.35 \\
(5.17)\end{array}$ & $\begin{array}{r}-1.72 \\
(2.40)\end{array}$ \\
\hline $\mathcal{U}$ & $\begin{array}{r}32.36 \\
(78.93)\end{array}$ & $\begin{array}{r}39.88 \\
(52.72)\end{array}$ & $\begin{array}{r}53.70 \\
(137.60)\end{array}$ & $\begin{array}{l}-4.01 \\
(9.70)\end{array}$ & $\begin{array}{r}22.02 \\
(44.69)\end{array}$ & $\begin{array}{r}11.22 \\
(31.70)\end{array}$ \\
\hline$\rho_{f g}$ & $\begin{array}{r}0.03 \\
(0.25)\end{array}$ & $\begin{array}{r}0.02 \\
(0.26)\end{array}$ & $\begin{array}{r}-0.01 \\
(0.30)\end{array}$ & $\begin{array}{r}0.07 \\
(0.15)\end{array}$ & $\begin{array}{r}0.01 \\
(0.23)\end{array}$ & $\begin{array}{r}-0.08 \\
(0.19)\end{array}$ \\
\hline
\end{tabular}

Numeraire: Germany; Period: 1994:III-1999:III; Moment Decompositions (7); Cross-Sectional standard deviations in parenthesis.

moment linkages we perform a multiple regression analysis for the rank ordered moment estimates. The reason for using rank-ordered instead of raw moments is that there are quite some outliers in the data, as we have seen before. For instance, the Bulgarian time series contain quite some extreme observations. In such circumstances the regular correlation coefficient is likely to be fragile, see Levine and Renelt (1992). To underpin our choice of rank association measure, we present in figure 1 the cross-country scatter plots for raw and rank-ordered fundamental average values $\mu_{f, i}$, and $\mu_{g, i}$ vis-a-vis the mean forex return $\mu_{s, i}$. At the top of each of the scatter plots we report the respective correlation estimate. These sample correlations are based on a cross-section of 30 countries. (The EMU data is excluded as noted before.) It can be seen that the choice of the metric underlying the association measure is of major importance for the 
Figure 1: Scatter Plot Averages

Left-hand side: point estimates;

Right-hand side: ranks of point estimates as \% of total.

Panel I: $\mu_{s}$ versus $\mu_{f}$

$\mu_{\mathrm{f}}$

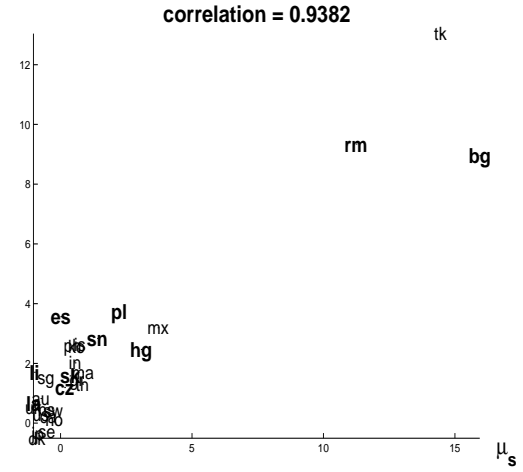

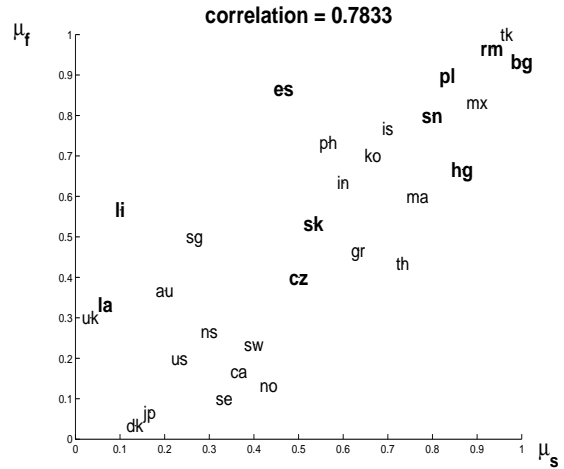

Panel II: $\mu_{s}$ versus $-\mu_{g}$
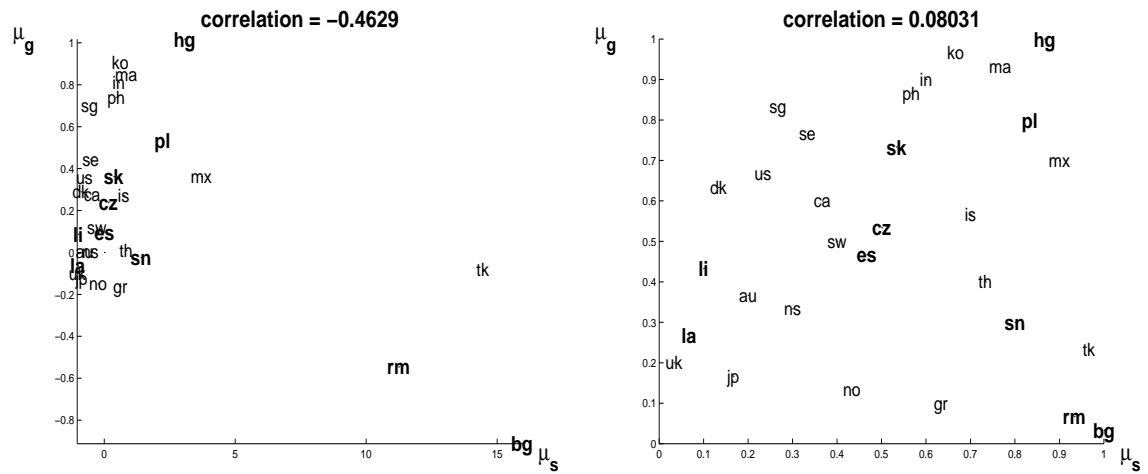

Numeraire: Germany; Period: 1994:III-1999:III;

outcomes. For example, take a look at the top panels in figure 1. The sample correlation coefficient for the pair $\left[\mu_{s, i}, \mu_{f, i}\right]$ is seen to be a substantial 0.94. But after a look at the scatter plot one must conclude that this association estimate is driven by a few outliers. Per contrast, when the data is rank-ordered first (see right top panel), the rank correlation estimate is lower, namely 0.78. In this case the scatter plot does not reveal an important 'Bulgaria effect'. Compared to the rank correlation, the regular correlation overestimates the association between $\mu_{s, i}$ and $\mu_{f, i}$ considerably. Even worse, from the lower panels in figure 1 it can be seen that just a few outliers may cause the correlation to switch its sign. Overall, the rank correlation appears to deliver the more robust results, and for this reason we use rank-ordered instead of raw moments in the cross-section analysis. 
Table 4: Multiple Rank Regressions Across Moments

\begin{tabular}{|c|c|c|c|c|c|c|}
\hline & $\mu_{s}$ & $\mu_{f}$ & $\mu_{g}$ & $\sigma_{s}^{2}$ & $\sigma_{f}^{2}$ & $\sigma_{g}^{2}$ \\
\hline$\mu_{s}$ & - & $\begin{array}{r}\mathbf{0 . 5 7} \\
(0.09)\end{array}$ & $\begin{array}{r}-0.03 \\
(0.28)\end{array}$ & $\begin{array}{r}0.29 \\
(0.20)\end{array}$ & $\begin{array}{c}-0.08 \\
(0.17)\end{array}$ & $\begin{array}{r}-0.09 \\
(0.20)\end{array}$ \\
\hline$\mu_{f}$ & $\begin{array}{r}\mathbf{0 . 8 5} \\
(0.19)\end{array}$ & - & $\begin{array}{c}-0.14 \\
(0.28)\end{array}$ & $\begin{array}{c}-0.17 \\
(0.25)\end{array}$ & $\begin{array}{r}\mathbf{0 . 3 9} \\
(0.21)\end{array}$ & $\begin{array}{r}0.41 \\
(0.25)\end{array}$ \\
\hline$\mu_{g}$ & $\begin{array}{r}-0.02 \\
(0.13)\end{array}$ & $\begin{array}{c}-0.04 \\
(0.09)\end{array}$ & - & $\begin{array}{r}-0.01 \\
(0.23)\end{array}$ & $\begin{array}{r}\mathbf{0 . 3 5} \\
(0.12)\end{array}$ & $\begin{array}{c}\mathbf{- 0 . 2 4} \\
(0.11)\end{array}$ \\
\hline$\sigma_{s}^{2}$ & $\begin{array}{r}0.16 \\
(0.14)\end{array}$ & $\begin{array}{r}-0.06 \\
(0.08)\end{array}$ & $\begin{array}{r}-0.01 \\
(0.26)\end{array}$ & - & $\begin{array}{r}0.01 \\
(0.16)\end{array}$ & $\begin{array}{r}0.12 \\
(0.17)\end{array}$ \\
\hline$\sigma_{f}^{2}$ & $\begin{array}{r}-0.07 \\
(0.16)\end{array}$ & $\begin{array}{r}\mathbf{0 . 2 3} \\
(0.10)\end{array}$ & $\begin{array}{r}\mathbf{0 . 6 3} \\
(0.20)\end{array}$ & $\begin{array}{r}0.01 \\
(0.25)\end{array}$ & - & $\begin{array}{r}\mathbf{0 . 4 7} \\
(0.18)\end{array}$ \\
\hline$\sigma_{g}^{2}$ & $\begin{array}{r}-0.07 \\
(0.16)\end{array}$ & $\begin{array}{r}\mathbf{0 . 2 3} \\
(0.12)\end{array}$ & $\begin{array}{l}\mathbf{- 0 . 4 2} \\
(0.12)\end{array}$ & $\begin{array}{r}0.19 \\
(0.25)\end{array}$ & $\begin{array}{r}\mathbf{0 . 4 6} \\
(0.19)\end{array}$ & - \\
\hline $\mathcal{D}^{\text {fix }}$ & $\begin{array}{r}2.58 \\
(3.51)\end{array}$ & $\begin{array}{r}-3.68 \\
(3.37)\end{array}$ & $\begin{array}{r}0.12 \\
(3.29)\end{array}$ & $\begin{array}{r}\mathbf{- 1 1 . 0 4} \\
(2.28)\end{array}$ & $\begin{array}{r}0.93 \\
(3.76)\end{array}$ & $\begin{array}{r}2.88 \\
(3.10)\end{array}$ \\
\hline intercept & $\begin{array}{r}1.85 \\
(3.27)\end{array}$ & $\begin{array}{r}1.79 \\
(2.74)\end{array}$ & $\begin{array}{l}\mathbf{1 4 . 9 1} \\
(5.85)\end{array}$ & $\begin{array}{l}\mathbf{1 2 . 4 3} \\
(4.73)\end{array}$ & $\begin{array}{r}-2.08 \\
(2.77)\end{array}$ & $\begin{array}{r}4.46 \\
(3.92)\end{array}$ \\
\hline
\end{tabular}

Numeraire: Germany; Period: 1994:III-1999:III; Cross-Section: CEEC and WEST\&REST; Multiple rank regression model (15); Standard errors in parenthesis. Bold faced values are significant at $5 \%$ level.

As explained above, we perform a multiple regression analysis for the rank ordered moment estimates in order to disentangle the cross-sectional variation in regime specifics. The dependent variable is the rank of an average value or variance. The rank regression results are reported in table 4. For example, in the first column of table 4 we report the results for the regression of the rank-ordered average forex return $\mu_{s, i}$ on an intercept, a regime dummy $\left(\mathcal{D}_{i}^{\mathrm{fix}}\right)$, the rank-ordered mean values of the fundamentals $\left(\mu_{f, i}\right.$ and $\left.\mu_{g, i}\right)$, and the rankordered volatilities $\left(\sigma_{s, i}^{2}, \sigma_{f, i}^{2}\right.$, and $\left.\sigma_{g, i}^{2}\right)$. We add the rigid forex regime dummy in order to measure a level effect of this regime. In table 1 we indicate to which countries a rigid regime has been assigned. All these countries had a fixed, or nearly fixed foreign rate regime vis-a-vis Germany at the beginning of the data sample, December 1993. We note that a flexible regime was assigned to Bulgaria because this country introduced the currency board vis-a-vis the euro not at the beginning but during the sample period, namely in $1997 .{ }^{5}$ Furthermore, we

\footnotetext{
${ }^{5}$ See for instance Gulde (1999).
} 
assigned flexible regimes to Lithuania and Latvia since these Baltic countries are not on a currency board vis-a-vis the euro, but instead vis-a-vis the dollar and SDE, respectively. ${ }^{6}$ We add the volatilities to the mean regressions in order to control for the premia associated with these risk factors. Similarly, the variance regressions are augmented with mean values in order to control for possible feedback from the premia to the risk factors. For more technical details see the Appendix A.3.

The partial effects between nominal mean values, $\mu_{s, i}$ and $\mu_{f, i}$, are still substantial in the multiple regressions, namely 0.85 and 0.57 , see the first and second column in table 4 . These highly significant values indicates that countries with low (high) average financial growth tended to experience small (sizeable) depreciations, and the other way around. The regression for $\mu_{f, i}$ also show that there are (weakly significant) positive mean-variance effects in the financial process. Countries with unstable markets were more likely to have high financial growth rates than countries with stable markets.

Interestingly, the slope coefficients on the financial and real volatilities have opposite signs, and significantly so, see third column table 4. This suggests that real growth rates are determined by a trade-off between financial and real stability. The highest real growth rates are observed in financial stable countries (low $\sigma_{f}^{2}$ ) where output increased along an unstable path (high $\sigma_{g}^{2}$ ). On the other hand, the lowest real growth rates are observed in financial unstable countries (low $\sigma_{f}^{2}$ ) where output fell along a deterministic trend (high $\sigma_{g}^{2}$ ). To sum up, it appears that financial certainty together with some flexibility in the production has been most advantageous for economic growth.

It is also of interest to examine partial volatility effects in the growth regression. Given real volatility, countries were more likely to have high (low) relative output growth if they had low (high) financial variability. Notice that the converse is also the case, in the sense that high-growth countries were more likely to have stable financial markets than low-growth countries, see the fifth column in table 4. Given the financial volatility, high-output-volatility countries were more likely to have higher relative output growth then low-output-volatility and vice versa (see last column table 4). What is also of interest is that there is a significant positive interrelationship between both fundamental volatilities. In particular, we obtained significantly positive estimates for the coefficient on $\sigma_{g}^{2}$ in the regression for $\sigma_{f}^{2}$, as well as for the coefficient on $\sigma_{f}^{2}$ in the regression for $\sigma_{g}^{2}$, see last two columns table 4 . This suggests that countries with the more (un)stable output market had a greater probability of having (un)stable

\footnotetext{
${ }^{6}$ See Rudgalvis (1996), and Viksnins (2000).
} 
financial trends and vice versa.

The adoption of a currency peg has a significant negative level effect on the forex volatility, see fourth column table 4 . Thus, as must be true almost by definition, we find that countries with rigid forex regimes tended to have lower forex volatility. Somewhat puzzling, and contrary to simple intuition, is that in the regression for $\sigma_{g}^{2}$ the coefficients on the fundamental volatilities $\left(\sigma_{f}^{2}\right.$ and $\left.\sigma_{g}^{2}\right)$ are insignificant. This indicates that fundamental uncertainty did not help explaining the forex uncertainty over and above the rigid forex regime level effect. It is of interest to note that bivariate sample (rank) correlations between fundamental volatilities and forex volatility are significantly positive (estimation results on request). To sum up, fundamental risks do matter for forex uncertainty if evaluated in isolation, but when information about the forex regime is taken into account these effects disappears.

Probably the most striking result of our empirical study is the flip side of the above result. Influences of the exchange rate variables on the real growth rate are apparently absent. The rigid regime dummy $\left(\mathcal{D}_{i}^{\text {fix }}\right)$, the average forex return $\left(\mu_{s}\right)$, as well as the forex volatility $\left(\sigma_{s}^{2}\right)$ do not contribute significantly to the explanation of the variation in the averages and variances of real growth rate $\left(\mu_{g}\right.$ and $\left.\sigma_{g}^{2}\right)$ across countries, see table 4 last two columns. This result is crucially important in light of our policy discussion. It supports the view that growth and fluctuations in the real sector are to a first-order unrelated to the adoption of a rigid exchange rate regime. Since we also find that high financial variability went hand-in-hand with low average growth, we conclude that economic growth is best served by providing domestic financial stability.

Some recent studies provide weak evidence that the choice of forex regime matters for the behavior of macro-economic fundamentals, but results are mixed, however, in the sense that there is no agreement on the regime-specific effects. ${ }^{7}$ In our view, the weakness and inconsistency of these empirical studies does support our claim that choice of the exchange rate regime is of lesser importance; what matters is the institutional structure within which domestic monetary and fiscal policies are formulated.

In order to assess whether or not our rank regression results are sensitive to the definition of the dependent nominal variable, we decide to repeat our analysis for the international price differential. ${ }^{8}$ If the rank regression coefficients change drastically when the nominal forex $s$ is replaced by the international

\footnotetext{
${ }^{7}$ Important contributions to the empirical literature on currency regimes include Ghosh, Gulde, Ostry and Wolf (1997), and Ghosh, Gulde and Wolf (1998) and Edwards (1996,98).

${ }^{8}$ In order to save space, these results are not reported here, but they will be made available on our web page in the near future.
} 
price differential $\widetilde{p}$, this would be unfavorable to our results. Overall, we find quite similar results as in table 4, which suggest that our rank regression is indeed robust to the definition of the endogenous nominal variable. For instance, just like the forex rate, the relative inflation rate has been insulated from domestic economic growth. It is further worthwhile mentioning that in the inflation rank regression analysis we find a significant negative link between the average fundamental values. It appears that economic growth goes hand in hand with financial expansion.

\subsection{The Forward Looking Model}

We found above evidence for the proposition that growth is to a first-order unrelated to the choice of forex regime. What does theory have to say on this matter? Consider the monetary model of the exchange rate (5) with time indices, but without residual

$$
s_{t}=\widetilde{m}_{t}-\tau \widetilde{y}_{t}+\lambda \widetilde{r}_{t}
$$

Suppose furthermore, that uncovered interest parity holds

$$
\widetilde{r}_{t}=E_{t}\left\{s_{t+1}-s_{t}\right\}
$$

where $E_{t}\left\{s_{t+1}\right\}$ is the time $t$ expected exchange rate for time $t+1$. Substitution into (8) and rearranging gives

$$
s_{t}=\frac{1}{(1+\lambda)}\left(\widetilde{m}_{t}-\tau \widetilde{y}_{t}\right)+\frac{\lambda}{(1+\lambda)} E_{t}\left\{s_{t+1}\right\} .
$$

Solving forward, we arrive at ${ }^{9}$

$$
s_{t}=\frac{1}{(1+\lambda)} \sum_{i=0}^{\infty} \frac{E_{t}\left\{\widetilde{m}_{t+i}-\tau \widetilde{y}_{t+i}\right\}}{(1+1 / \lambda)^{i}} .
$$

The stability of $\left\{s_{t}\right\}$ has to be achieved by stabilizing the expectations regarding the fundamental process $\left\{\widetilde{m}_{t+i}-\tau \widetilde{y}_{t+i}\right\}$. In summary, the folk theorem of exchange rate economics maintains:

Theorem 1 The current exchange rate is determined by the discounted sum of all future expected fundamentals.

\footnotetext{
${ }^{9}$ We do not necessarily rule out the bubble solution (see below). It be noted, though, that empirical evidence has not generated much evidence for the bubble solutions.
} 
What does the theorem imply for the relation between the variability of the forex return process $\left\{\Delta s_{t}\right\}$ and the fundamental growth process $\left\{\Delta \widetilde{m}_{t+i}-\right.$ $\left.\tau \widetilde{y} \Delta_{t+i}\right\}$ ? Suppose that the composite fundamental, $z_{t}=\widetilde{m}_{t}-\tau \widetilde{y}_{t}$, follows a driftless random walk

$$
z_{t+1}=z_{t}+\sigma_{\xi} \xi_{t+1}
$$

where $\left\{\xi_{t+1}\right\}$ is assumed to be a white noise process. In that case $E_{t}\left\{\Delta z_{t+i}\right\}=$ $\sigma_{\xi} E_{t}\left\{\xi_{t+1}\right\}=0$ for all $i$. Under this condition the forward solution of the forex rate (10) implies that $\Delta s_{t}=\Delta z_{t}$. Consequently, the behavior of the composite fundamental, $z_{t}$, is transferred, one for one, to the exchange rate, $s_{t}$. It be noted that the random walk model (11) is somewhat restrictive since it implies that the interest differential is always zero $\widetilde{r}_{t}=E_{t}\left\{\Delta s_{t+1}\right\}=0$ which is clearly counterfactual. Nevertheless, it also part of the folk wisdom on exchange rate economics that $\left\{s_{t}\right\}$ approximately follows a random walk. Anyway, the result below does not depend critically on the random walk assumption; see next sub-section

Corollary 1 Under the assumption that the composite fundamental process $\left\{z_{t}\right\}$ follows a random walk with white noise innovation process $\left\{\xi_{t}\right\}$, the volatility of the composite fundamental is transferred, one for one, to the exchange rate $\sigma_{z}^{2}=\sigma_{\xi}^{2}=\sigma_{s}^{2}$. But it does not follow from Theorem 1 that, in a multiple (rank) regression, the variability of exchange rate, $\sigma_{s}^{2}$, depends significantly on the fundamental volatilities, $\sigma_{f}^{2}$ and $\sigma_{g}^{2}$.

It may thus happen that $\sigma_{z}^{2}$ itself is low (high), while each of the individual fundamental variances, $\sigma_{f}^{2}$ and $\sigma_{g}^{2}$, are high (low). One extreme possibility is that output and money move in tandem, so that $\sigma_{z}^{2}=0=\sigma_{s}^{2}$. In fact, this situation is exactly what the single monetary policy and the Growth and Stability Pact is all about. This pact should ensure that correlation between local financial and real economic variables increases. It is for these reasons that output growth can be unrelated to the forex variable. Seen in this way, our multiple rank regression results are consistent with the theory on forex rates.

Two important policy conclusions follow. First, due to the forward looking nature of the forex market, exchange rate stability hinges on the stability of the institutional structure within which monetary and fiscal policies are formulated. More uncertainty in the money market translates into more uncertainty in the forex market. Seen in this way, a flexible exchange rate can be very stable, if the current and anticipated monetary and fiscal policies are coherent with the current rate, as countries like Switzerland and The Netherlands have shown. 
Conversely, as is illustrated by the lively history of the EMS and other currency arrangements, a managed float or fixed rate system can be very unstable.

Policy makers should also accept that the usefulness of a currency peg depends on the quality of the institutional structure and the degree of business cycle synchronization. Asymmetric and persistent real shocks render all markets unstable, even under a currency peg. Due to institutional underdevelopment capital is not invested efficiently, and the peg may come under attack. In the presence of asymmetric shocks and inefficiencies, the forex remains a useful automatic stabilizer. For smaller economies asymmetric real shocks are probably much less important because they are relatively open to trade. ${ }^{10}$

We end the section with two observations. First, it is well known that the complete solution under rational expectations for $s_{t}=(1+1 / \lambda)^{t} c_{t}$, where $E\left[c_{t+1}\right]=c_{t}$, also comprises a bubble part. But it is easily shown that this does not affect the propositions qualitatively (not even if $c_{t}=z_{t}$ ).

Second, as we noted above, the random walk assumption has the counterfactual implication that the interest differential is always zero. To break away from this implication, suppose that a risk premium $\pi_{t}$ enters the uncovered interest parity condition (9). In that case the interest differential obeys

$$
\widetilde{r}_{t}=E_{t}\left\{s_{t+1}-s_{t}+\pi_{t}\right\}
$$

Substitution into (8), and solving forward under the maintained assumption that fundamentals follow a random walk, one arrives at

$$
s_{t}=z_{t}+\frac{\lambda}{1+\lambda} \sum_{i=0}^{\infty} \frac{E_{t}\left\{\pi_{t+i}\right\}}{(1+1 / \lambda)^{i}} .
$$

This equation again describes how the current exchange rate depends on the expected path of fundamentals and, in addition, on the expected future risk premia. Since the risk premium process $\left\{\pi_{t+i}\right\}$ is generally a function of the fundamental process $\left\{z_{t+i}\right\}$, we can assume that the expected risk premium $E_{t}\left\{\pi_{t+i}\right\}$ is a function of the fundamentals $z_{t}$. The qualitative results from theorem 1 and corollary 1 again carry over.

\footnotetext{
${ }^{10}$ For a detailed discussion of the advantages and disadvantages of exchange rate targeting, see Williamson (1995), Ghosh et al. (1998), and Calvo and Reinhart (2000). The exchange rate option of currency boards for CEECs is analyzed thoroughly by Rudgalvis (1996), and Viksnins (2000) for the Baltic Republics, and Gulde (1999) for Bulgaria.
} 


\section{EMU Entry of Accession Countries}

In this section we analyze in detail the endogenous response to accession to EMU. ${ }^{11}$ In order to draw a comparison between pre- and post-entry monetary status, we first characterize the these two situations on basis of the standard monetary theory. It turns out that EMU entry is likely to lead to a significant reduction of the country-specific financial risk. Furthermore, due to the forward looking nature of financial markets, the CEEC may bring forward the benefits of EMU entry through a credible announcement of entry at some future date.

\subsection{Endogenous Responses to Entry}

The flexible forex model (5) is the starting point of our analysis of the endogenous responses to entry. To stress the fact that entry is likely to lead to a structural change of fundamental processes, we use throughout a superscript 'post' to indicate the ex post processes.

When a country enters the monetary union at time $t=\bar{t}$, its forex rate is fixed at a level $\bar{s}$. Consequently the noisy component $\nu_{t}$ in the PPP condition (5) is restricted to equal zero

$$
s_{t}^{\text {post }}=\bar{s}=\kappa+\widetilde{p}_{t}^{\text {post }}, \text { for } t \geq \bar{t}
$$

Assuming that uncovered interest parity (9) holds, it follows also that the interest differential is zero

$$
\widetilde{r}_{t}^{\text {post }}=E_{t}\left\{\Delta s_{t+1}^{\text {post }}\right\}=E_{t}\{\bar{s}-\bar{s}\}=0, \text { for } t \geq \bar{t}
$$

Taken together, through monetary unification a country eliminates forex and interest risk. Imposing restrictions (12) onto the forex rate model (5) shows that the nominal forex return after monetary unification obeys the relationship

$$
\Delta \bar{s}=\beta \Delta \widetilde{m}^{\text {post }}-\tau \Delta \widetilde{y}^{\text {post }}-\Delta \widetilde{\varepsilon}^{\text {post }}=0
$$

Note also that due to the forex peg, the real forex return equals the international inflation differential after entry. Formally, the real forex rate is defined as $w_{t}=$ $\widetilde{p}_{t}-s_{t}$. After entry $w_{t}^{\text {post }}=\widetilde{p}_{t}^{\text {post }}-\bar{s}$, so log growth rates obey $\Delta w_{t}^{\text {post }}=\Delta \widetilde{p}_{t}^{\text {post }}$.

As before, in order to characterize the monetary policy regime, we calculate

\footnotetext{
${ }^{11}$ Arnold and de Vries (2000a,b) used a similar argument but in a different context, they investigate the implications of EMU for the first wave of entries into EMU.
} 
the forex return's moment decompositions

$$
\begin{aligned}
& 0=\beta \mu_{m}^{\text {post }}-\tau \mu_{y}^{\text {post }}+\mathcal{E}^{\text {post }} \\
& 0=\beta^{2} \sigma_{m}^{2 \text { post }}+\tau^{2} \sigma_{y}^{2 \text { post }}+\beta \tau \sigma_{m y}^{\text {post }}+\mathcal{U}^{\text {post }}
\end{aligned}
$$

Other things equal, the post-accession financial growth rates are likely to be much smaller and more stable than their pre-entry counterparts (7). The reason is that participation in the EMU eliminates the noise component $\nu$ and the interest differential $\Delta \widetilde{r}$. Besides this direct effect, monetary unification is also likely to trigger indirect endogenous responses in financial and real sectors. First, it is likely to lead to a reduction of country-specific financial risk. Participating countries in the EMU showed a higher convergence of monetary policy variables than nonparticipating countries. ${ }^{12}$ This nominal risk reduction is likely to be conducive for output growth. Secondly, in the longer run it is most probable that EMU entry will lead to a structural fall of the relative production volatility. Due the single monetary policy and the Growth and Stability Pact, the EMU countries showed a stronger business cycle synchronization than nonparticipating countries. ${ }^{13}$

\subsection{Entry Announcement}

According to the forward solution of the monetary model an entry announcement not only forces a prediction on the current behavior of the forex variable, but also on the speed of convergence of policy variables. We illustrate this by considering the hypothetical situation in which an accession country is allowed to enter EMU after 2 years at the exchange rate $\bar{s}$.

The forex rate before the entry announcement obeys the forward solution of the monetary model (10) truncated at time $t+2$, i.e.

$$
s_{t}=\frac{1}{(1+\lambda)} E_{t}\left\{z_{t}\right\}+\frac{\lambda}{(1+\lambda)^{2}} E_{t}\left\{z_{t+1}\right\}+\frac{\lambda^{2}}{(1+\lambda)^{2}} E_{t}\left\{s_{t+2}\right\} .
$$

At time $t$ it is announced that after 2 years the exchange rate is fixed at $\bar{s}$. When this announcement is credible, the expectations converge to the announced rate $E_{t}\left\{s_{t+2}\right\}=\bar{s}$, and as a consequence the forex rate after the entry announcement

\footnotetext{
${ }^{12}$ See e.g., Brada and Kutan (2001). They find "significant long- and short-run linkages between German base money stock and that of the most recent members of the EU; the same holds true for the non-transition economies". By contrast, the monetary bases of the CEECs appear only weakly linked to that of Germany, or even unrelated.

${ }^{13}$ See e.g., Artis and Zhang (1995), and Fatas (1997). In fact, also in case of CEECs the trade links and synchronization of business cycles with EU are already increasing, see Fidrmuc (2001).
} 
obeys

$$
s_{t}^{\text {post }}=\frac{1}{(1+\lambda)} z_{t}+\frac{\lambda}{(1+\lambda)^{2}} E_{t}\left\{z_{t+1}\right\}+\frac{\lambda^{2}}{(1+\lambda)^{2}} \bar{s} .
$$

We see that the announcement forces the current forex rate to jump to a new path that is consistent with $s_{t+2}=\bar{s}$. But ipso facto, the model forces a prediction on the current behavior of policy variables as well. The path $\left\{s_{t}^{\mathrm{fix}}\right\}$ can only be achieved if the path of the policy variables is consistent with this path. Since from time $t+2$ onward $s_{t}=\bar{s}$, necessarily

$$
s_{t+2}=\bar{s}_{t+2}=\ldots=\bar{s}=\frac{1}{(1+\lambda)} \sum_{i=0}^{\infty} \frac{E_{t+2}\left\{z_{t+2+i}\right\}}{(1+1 / \lambda)^{i}}
$$

which constrains all future paths of $z_{t+2+i}$. One option is to keep domestic and foreign variable in tandem, which is exactly what the single monetary policy and the Growth and Stability Pact is all about. When the announced parity is not in line with the future fundamental drivers, sooner or later a speculative attack takes place.

An important policy implication of the above result is that the consistent future fundamental paths can only be realized for some particular set of fundamental growth rates, given the initial fundamental values. For this reason the policy variables may converge fast! As the cases of Italy and Portugal showed, the perspective of entry brings forward the benefits of eliminating the currency risk premium from the domestic interest rate. It can thus be argued that an entry announcement provides a free lunch in the sense of lowering the commitment costs, since many alternative paths are closed off (and at the cost that the fundamental variables have indeed to be set consistent with the announced path). Seen in this way, the forward looking nature of the forex provides an argument for fast EMU accession.

\section{EMU Accession Criteria and Euroisation}

The direct and indirect endogenous responses sketched in the previous subsections provide a strong argument in favor of EMU accession. However, to enter EMU the accession countries need to satisfy the EMU accession criteria, or so-called "Copenhagen Criteria", which are put down in the Composite Paper, see European Commission (1998). In this section we analyze the feasibility of two of these criteria, namely the low inflation, and stable currency criteria for entry into EMU. Roughly, these criteria state that during two years 
before accession, the forex should be stable and inflation should be equal (or lower) than the aggregate EMU inflation rate. We conclude that it is very difficult for the accession countries to simultaneously satisfy the low inflation, and stable currency criteria. Fortunately, there is a possible escape route through euroisation.

\subsection{Feasibility of EMU Accession Criteria}

CEECs are very likely to experience higher domestic inflation than current EMU members due to the Balassa-Samuelson effect. Standard international economics theory predicts that the labor productivity in the service oriented non-traded goods sector grows less rapidly (relative to the incumbent countries) in comparison to the labor productivity catch up in the traded goods sector. If wages are equalized across sectors, prices of the non-traded goods in CEECs will be rising faster, and cause apparent inflation. ${ }^{14}$ When the Balassa-Samuelson effect turns out to be weak, this is good news for local policy makers in CEECs who aim to bring down local inflation rates to EMU levels. However, when the Balassa-Samuelson effect is strong, the perspective of EMU entry is not flourishing. Since high local inflation is not permitted within EMU, the CEECs that want to enter EMU would have to contract output in order to countervail the inflationary pressures from the catching-up effects.

Most empirical studies do find evidence for the Balassa-Samuelson effect, see for example, Canzoneri, Cumby and Diba (1999), or Sinn and Reutter (2001). In light of our policy discussion, the results of Sinn and Reutter (2001) are particularly interesting since they look at Balassa-Samuelson effects within EMU, as well as within a hypothetical enlarged EMU. They find that BalassaSamuelson effects cause prices in Finland, Ireland, Spain, and the Netherlands to rise faster than in Germany. Moreover, they predict that when the CEECs enter in EMU the Balassa-Samuelson effects will become more pronounced, leading to an even higher aggregate EMU inflation rate.

Our own rank regression results for the international inflation differential (not presented here) also provide evidence for a Balassa-Samuelson effect in terms of financial growth rates, not in terns of inflation rates. We find that there is a significant negative relation between the fundamental growth rates $\mu_{f}$ and $\mu_{g}$ if relative inflation is taken into account. This indicates that expansionary (contractionary) monetary policy was related to high (low) economic growth

\footnotetext{
${ }^{14}$ See Balassa (1964), and Samuelson $(1964,1994)$. A competing strategy to explain the persistent high inflation is the relative factor endowments theory of Kravis and Lipsey (1988) and Bhagwati (1984). Yet another competing theory is the Lindner-type hypothesis which stresses the role of demand factors, see e.g. Bergstrand (1991).
} 
rates, and vice versa. Consequently, accession countries have a problem to give a fully credible signal that their excessive financial growth is due to catch-up effects in productivity, and are not due to lack of monetary prudence. If these countries cannot give such a signal, they might have to reduce economic growth to counter high financial growth rates.

Exchange rate targeting gives rise to persistent oscillations in the real interest rate and the real exchange rate due to the 'Walters' effect'. ${ }^{15}$ Walters' critique of premature pegging attempts, is build on the main argument that high-inflation countries are characterized by inappropriately low real interest rates. Consequently, fixed forces rates induce foreign capital that fuels a local investment bubble. In the longer run, financial markets will recognize the local investment bubble, and try to retrieve their capital. To keep the foreign capital within the borders, the local authorities must promise higher nominal interest rates. If they opt not to use the interest instrument, they have to abandon the currency peg. Premature attempts to fix exchange rates are especially dangerous for institutionally underdeveloped countries, such as the CEECs. The anticipation of a stable path for the exchange rate in the short run, invites for speculative capital inflows. The risk is that without the necessary checks and balances in capital markets due to institutional underdevelopment, capital inflows may not be allocated efficiently. In the longer run the capital inflows reverse themselves on the smallest doubt, thereby triggering a speculative attack. To resist such attacks the CEEC may have to raise its interest rates to delirious levels, otherwise it will have to abandon the currency peg. The interest rate hike is detrimental to local investment and activity, which may trigger a devaluation for this reason. Recall, for instance the Irish and British interest rate hikes during the EMS crisis.

\subsection{Euroisation; A Resolution?}

In the previous subsection it was argued that, due to the Balassa-Samuelson effects, local inflation rates in CEECs are expected be above the EMU average for quite some time. It was also noted that high-inflation countries which peg their currencies to the euro are likely to undergo persistent oscillations in the real interest rate and the real exchange rate, due to the Walters' effect. Furthermore, the stable currency criterion can give rise to detrimental self-fulfilling cycle of delay. To sum up, EMU entry seems to be out of the question, at least in the

\footnotetext{
${ }^{15}$ Former advisor to UK prime minister Margaret Thatcher, Sir Alan Walters, opposed the entry of UK to EMS by pointing out the risk of interest rate hikes, see Walters (1986). Recently, Leitemo and Røisland (2000) developed a monetary model that incorporates the "Walters' effect".
} 
short-run. In this subsection we propose a resolution, namely the exchange rate option of euroisation. ${ }^{16}$

If a CEEC euro-ises completely, its currency risk premium will be gone. Formally, in the monetary forex model euroisation amounts to setting the nominal forex equal to unity $s_{t}=0$ for all $t>\bar{t}$, where $\bar{t}$ is the date of euroisation. It follows that we can apply the post-entry conditions (12) discussed in the previous subsection. The fixing of the forex eliminates the interest rate differential and the forex risk: $\widetilde{r}_{t}^{\text {post }}=\nu_{t}=0$, for $t \geq \bar{t}$. More restrictive than before, euroisation implies a zero $\log$ forex rate, $s_{t}^{\text {post }}=0$. The PPP supposition (5) states that relative prices equal the wedge: $\widetilde{p}_{t}^{\text {post }}=\kappa$. Accordingly, we evaluate the post-euroisation situation on basis of the relative pricing relationship (3). The post-euroisation relative pricing relationship reads

$$
\widetilde{p}_{t}^{\text {post }}=\beta \widetilde{m}_{t}^{\text {post }}-\tau \widetilde{y}_{t}^{\text {post }}-\widetilde{\varepsilon}_{t}^{\text {post }}
$$

If there is a Balassa-Samuelson effect, then the euro-ised CEECs' aggregate price level rises persistently relative to the EMU, $E\left\{\widetilde{p}_{t}^{\text {post }}\right\}>0$, at the same time production will also rise relative to EMU, $E\left\{\widetilde{y}_{t}^{\text {post }}\right\}>0$. But then the monetarist model predicts that $E\left\{\widetilde{m}_{t}^{\text {post }}\right\}=E\left\{\widetilde{p}_{t}^{\text {post }}\right\}+\tau E\left\{\widetilde{y}_{t}^{\text {post }}\right\}>0$. As a consequence of the Balassa-Samuelson effect money demand will be high in the CEECs as compared to EMU area. Through complete euroisation the CEEC can give a fully credible signal that its 'high inflation' and, especially its 'excessive money growth' is the result of inter-sectorial productivity asymmetries, and not due to lack of monetary prudence.

\section{Summary and Concluding Remarks}

This paper claims that the choice of forex regime is not of first order importance for economic growth. This claim was founded on empirical evidence that forex returns does not help explain economic growth, nor does a fixed regime dummy. A priori, the canonical forex model allows for both possibilities. The model certainly does not imply that the choice of regime is important for growth as we found empirically. The result that economic growth is insulated from the exchange rate variable carries a very positive message for policy makers supporting the view that the choice of forex regime is irrelevant. Policy can focus on providing monetary stability, since it is monetary stability that is

\footnotetext{
${ }^{16}$ Euroisation is the Europe's counterpart to dollarisation in the Americas. The exchange rate option of euroisation for CEECs is examined in detail by Nuti (2000), and Schoors (2001), amongst others. Dollarization is analyzed thoroughly by LeBaron and McCulloch (2000).
} 
conducive to growth.

It is showed next that standard monetary theory predicts that country specific financial risk will reduce significantly upon entry in EMU. Furthermore, due to the forward looking nature of the forex, a credible entry announcement does not only have implications for the future forex rate behavior, but it also restricts the future behavior of fundamental drivers. At the same time, the forward looking nature brings forward the benefits of eventual entry.

The paper also argues that the EMU accession criteria for low inflation and stable currency are too rigid. Especially when the Balassa-Samuelson effect is strong, the perspective of EMU entry is not prosperous. Since high local inflation is not permitted, the CEECs would have to contract output in order to countervail the inflationary pressures originating from the catching-up effects To avoid the latter undesirable scenario, the incumbent EMU members must be prepared to accept multiple Irelands for a number of years. Perhaps the EMU's Harmonized Consumer Price Index should be calculated only on the basis of the price levels in the present EMU member countries for some time after the entry of the CEEC.

The final conclusion is a subscription to an unconventional recipe. We argue that by a full scale euroisation upon receipt of entry (commitment) from the EU, the smaller countries could cross-out any remaining exchange rate and interest rate uncertainty. At the same time such an arrangement would make clear that the remaining inflationary pressures are entirely due to real factors, such as the Balassa-Samuelson effect, and cannot be the result of imprudent monetary policy on the side of CEECs.

\section{References}

Arnold, I.J.M and C.G. de Vries, "Endogeneity in European money demand," European Journal of Political Economy, 2000a.

Arnold, I.J.M. and C.G. de Vries, "Endogenous financial structure and the transmission of ECB policy," in J. Von Hagen and C. Waller, eds., Regional Aspects of Monetary Policy in Europe, Dordrecht: Kluwer Academic Publishers, 2000b, pp. 193-220.

Artis, M.J. and W. Zhang, "International business cycles and the ERM: Is there a European business cycle?," CEPR discussion paper, 1995, 1191.

Bacchetta, P. and E. van Wincoop, "Does exchange-rate stability increase trade and welfare?," American Economic Review, 2000, 90, 1093-1109.

Balassa, B., "The purchasing power parity doctrine: A reappraisal," Journal of Political Economy, 1964, 72, 584-596.

Bergstrand, J.H., "Structural determinants of real exchange rates and natural price levels: Some empirical evidence," American Economic Review, 1991, 81, 325-334. 
Bhagwati, J.N., "Why are services cheaper in poor countries?," Economic Journal, 1984, 94, 279-286.

Brada, J.C. and A.M. Kutan, "The convergence of monetary policy between candidate countries and the European Union," ZEI Policy Paper, 2001, B07-2001. Available at: http://www.zei.de/download/zei_wp/B01-07.pdf.

Calvo, G.A. and C.M. Reinhart, "Fixing for your life," NBER Working Paper, 2000, 8006. Available at: http://papers.nber.org/papers/W8006.pdf.

Canzoneri, M.B., R.E. Cumby, and B. Diba, "Relative labor productivity and the real exchange rate in the long run: evidence for a panel of OECD countries," Journal of International Economics, 1999, 47, 245-266.

Davidson, R. and J.G. MacKinnon, Estimation and inference in econometrics, New York: Oxford University Press, 1993.

Edwards, S., "The Determinants of the Choice Between Fixed and Flexible Exchange-Rate Regimes," NBER Working Paper, 1996, 5756. Available at: http://papers.nber.org/papers/w5756.pdf.

"Exchange Rate Anchors and Inflation: A Political Economy Approach.," in S Eijffinger and H. Huizinga, eds., Positive Political Economy: Theory and Evidence, Cambridge University Press Cambridge, UK 1998, pp. 187-212.

European Commission, "Composite Paper," EC Brussels, 1998.

Fatas, A., "EMU: Countries or regions? Lessons from the EMS experience," European Economic Review, 1997, 41, 743-751.

Fidrmuc, J., "The endogeneity of the optimum currency area criteria, intraindustry trade, and EMU enlargement," LICOS Discussion Paper, 2001, 106.

Ghosh, A.R., A.M Gulde, and H.C. Wolf, "Currency boards: The ultimate fix?," International Monetary Fund Working Paper, 1998, 98/8. Available at: http://www.imf .org/external/pubs/ft/wp/wp9808.pdf.

, A.M. Gulde, J.D. Ostry, and H.C. Wolf, "Does the nominal exchange rate regime matter?," NBER Working Paper, 1997, 5874. Available at: http://papers.nber.org/papers/W5874.pdf.

Gulde, A.M., "The role of the currency board in Bulgaria's stabilization," International Monetary Fund Policy Discussion Paper, 1999, 99/3. Available at: http://www.imf .org/external/pubs/ft/pdp/1999/pdp03.pdf.

Kravis, L.B. and R.E. Lipsey, "National price levels and the prices of tradables and non-tradables," American Economic Review, 1988, 78, 474-478.

LeBaron, B. and R. McCulloch, "Floating, fixed, or super-fixed? Dollarisation joins the menu of exchange rate options," American Economic Review, 2000, 90, 34-37.

Leitemo, K. and $\varnothing$. Røisland, "The choice of monetary policy regime for small open economies," Norges Bank's Working Paper, 2000, 2000/5. Available at: http://www.norges-bank.no/publikasjoner/arbeidsnotater.

Levine, R. and D. Renelt, "A sensitivity analysis of cross-country growth regressions," American Economic Review, 1992, 82, 942-963.

Lucas, Junior R.E., "Econometric policy evaluation: A critique," Carnegie-Rochester Conference Series on Public Policy, 1976, 1, 59-46. 
Nuti, D.M., "The costs and benefits of euro-isation in CentralEastern Europe before or instead of EMU membership," William Davidson Institute Working Paper, 2000, $340 . \quad$ Available at: http://eres.bus. umich.edu/docs/workpap-dav/wp340.pdf.

Rudgalvis, K., "Establishing a new currency and exchange rate determination: The case of Lithuania," Centre for Economic Reform and Transformation Discussion Paper, 1996, 96/4. Available at: http://www.hw.ac.uk/ecoWWW/cert/wpa/1996.

Samuelson, P.A., "Theoretical notes on trade problems," Review of Economics and Statistics, 1964, 46, 145-154.

Schoors, K., "The EU and its Eastern European accession countries; Should they adopt the EURO before or after accession?," Unpublished Manuscript, 2001.

Sinn, H.W. and M. Reutter, "The minimum inflation rate for Euroland," NBER Working Paper, 2001, 8085. Available at: http://papers.nber.org/papers.

Stock, J.H. and M.W. Watson, "A simple estimator of cointegrating vectors in higher order integrated systems," Econometrica, 1995, 61, 783-820.

Viksnins, G.J., "Baltic monetary regimes in the XXIst century," Georgetown University Economics Discussion Paper, 2000, 00-02. Available at: http://www.georgetown.edu/faculty/viksning/papers.

Walters, A., Britain's Economic Renaissance, Oxford University Press, 1986.

Williamson, J., "What role for currency boards?," Policy Analyses In International Economics, 1995, 40. Available at: http://www.iie.com/publications.

\section{A Appendix}

In the near future a more detailed appendix will be made available on line.

\section{A.1 Panel Data Description}

We analyze a panel data set containing quarterly monetary data for the CEECs, the EMU, and other industrialized countries. Throughout the numeraire country is Germany. The panel covers 40 countries (excluding Germany) over the period 1993:4 1999:3 (24 observations per country). The exact composition of the country groupings is given by table 1 . Our main data source is the International Financial Statistics (IFS) data base. The following time series were used. The forex rate $S$ is the National Currency per US Dollar (lines AE and $A G$ IFS). When the forex series was provided in English denomination (lines $A G$ IFS), we inverted it to obtain the continental notation. Deutsche mark exchange rates are derived using the triangle arbitrage rule. The output $Y$ is Industrial Production (lines 66 IFS), with exception of the CEECs. For Hungary, Poland, Romania, and Slovenia the output is measured by GDP in historic market prices. For the other CEECs the available output measure was GDP in current market prices, which are deflated on basis of the consumer price index. 
The money stock $M$ is Money plus Quasi-Money (lines 34 and 35 IFS), with exception of some CEECs in which case the money series were downloaded from the national bank. The Interest $R$ is Lending Rate (lines 60P IFS). When the lending rate series are unavailable or incomplete, we use the Deposit Rate (lines $60 L$ IFS). Output and money are seasonally adjusted, and the data for $s, \widetilde{m}$, and $\widetilde{y}$ are taken in deviation from their mean, to account for scale differences between the country variables.

\section{A.2 Panel Dynamic OLS Estimation}

The coefficients of model (5) are estimated using the panel version of the Stock and Watson's dynamic OLS procedure. ${ }^{17}$ This panel dynamic OLS estimation consists of a regression between the levels $s, \widetilde{m}, \widetilde{y}, \widetilde{r}$, year dummies $d_{a, t}$ (equal to unity in year $a$ ), seasonal quarter dummies $d_{q, t}$ (equal to unity in quarter $q$ ), as well as the one-period leads and lags:

$$
\begin{aligned}
s_{i, t} & =c+\beta \widetilde{m}_{i, t}+\lambda \widetilde{r}_{i, t}-\tau \widetilde{y}_{i, t}+d_{a, t}+d_{q, t} \\
& +a_{i, 1} \Delta \widetilde{m}_{i, t-1}+a_{i, 2} \Delta \widetilde{y}_{i, t-1}+a_{i, 3} \Delta \widetilde{r}_{i, t-1} \\
& +a_{i, 4} \Delta \widetilde{m}_{i, t+1}+a_{i, 5} \Delta \widetilde{y}_{i, t+1}+a_{i, 6} \Delta \widetilde{r}_{i, t+1}+e_{i, t},
\end{aligned}
$$

for $i=1, \ldots, N, t=1, \ldots, T$. Our main interest lies in the long-run coefficients $(\beta, \tau$, and $\lambda)$. To save space we do not report the coefficients on the seasonal dummies, nor the coefficients on the leads and lags.

To see whether the cointegrating vector applies to the panel, we run the pooled Augmented Engle-Granger (AEG) test regression for panel residuals

$$
\Delta e_{i, t}=\gamma e_{i, s-1}+\gamma_{1} \Delta e_{i, t-1}+\gamma_{2} \Delta e_{i, t-2}+u_{i, t}
$$

for $i=1, \ldots, N, t=1, \ldots, T$. The null is a unit root $H_{0}: e_{i, t} \sim I(1)$, which corresponds to parameter restriction $\gamma=0$. The choice of critical values is determined by six factors, for which we assume the following: ( $i$ ) The number of non-stationary variables on the RHS equals 3 ; (ii) The residual $e_{i, t}$ is stationary; (iii) The number of countries $N$ remains fixed forever; (iv) Time $T$ expands forever; $(v)$ Non-stochastic regressors are excluded; and $(v i)$ The

\footnotetext{
${ }^{17}$ It is well-known that the appropriate technique to estimate the foreign exchange rate model (5) depends on the time series behavior of exchange rates, money, output, and interest rates. Are these variables are individually integrated of order one and cointegrated?

Given that the time period available for estimation is short, the time series unit root tests are doomed to fail; to test properly for a unit root one needs lots of observations, while we have at most 24 quarterly observations per country. We did test for unit roots and cointegration for each individual country. As expected, the null hypotheses of unit roots and cointegration are rejected in most cases.
} 
residuals $e_{i, t}$ are perfectly correlated across countries. Notice that assumption (vi) guarantees that the pooled test essentially collapses to a single time series test. Under assumptions $(i)$ to $(v i)$, the appropriate asymptotic critical values are those reported in table 20.2 in Davidson and MacKinnon (1993). At the $5 \%$ level, MacKinnon's critical value equals -3.74 .

\section{A.3 Multiple Rank Regressions}

To perform the multiple rank regression, we stack the expected values and variances into an $(N \times 6)$ matrix $Q$. Writing out this matrix explicitly

$$
Q=\left[\begin{array}{cccccc}
\mu_{s, 1} & \mu_{f, 1} & \mu_{g, 1} & \sigma_{s, 1}^{2} & \sigma_{f, 1}^{2} & \sigma_{g, 1}^{2} \\
\mu_{s, 2} & \mu_{f, 2} & \mu_{g, 2} & \sigma_{s, 2}^{2} & \sigma_{f, 2}^{2} & \sigma_{g, 2}^{2} \\
\vdots & \vdots & \vdots & \vdots & \vdots & \vdots \\
\mu_{s, N} & \mu_{f, N} & \mu_{g, N} & \sigma_{s, N}^{2} & \sigma_{f, N}^{2} & \sigma_{g, N}^{2}
\end{array}\right] \text {. }
$$

Let $q_{i, m}$ be a typical element of the matrix $Q$. Next, we construct an $(N \times 6)$ rank-ordered matrix $Q^{r}$ with typical element $q_{i, m}^{r}$ that is equal to the ascending rank order of the element $q_{i, m}$ in matrix $Q$. Thus if $q_{i, m}$ is the smallest value in column $m$, then $q_{i, m}^{r}=1$; if $q_{i, m}$ is the second smallest value in column $m$ then $q_{i, m}^{r}=2$; etc. In order to measure a level effect of a rigid forex regime, we construct a rigid regime dummy $\mathcal{D}_{i}^{\text {fix }}$ which equals unity if country $i$ has a rigid forex regime, otherwise it equals zero.

The multiple rank regression involves an OLS regression of a specific column in $Q^{r}$ on all other columns in $Q^{r}$, a constant $\mathbf{1}$, and a regime dummy $\mathcal{D}_{i}^{\mathrm{fix}}$, that is

$$
q_{i, m}^{r}=a \mathbf{1}+b \mathcal{D}_{i}^{\mathrm{fix}}+\sum_{k}^{5} \alpha_{m, k} q_{i, k}^{r}+\epsilon_{i, m}, \quad k \neq m
$$

for $i=1, \ldots, N$.Here $\epsilon_{i, m}$ is the residual. We test the null hypotheses that the partial relations between columns $m$ and $k$ are absent, $H_{0}: \alpha_{m, k}=0$, and that there is no rigid regime level effect: $H_{0}: b=0$. 